\section{Ultrasonographic, quantitative comparison of lower extremity lymphedema versus normal control. Technical note with case reports}

\author{
Vanessa Lôbo de Carvalho, ${ }^{1}$ \\ Sergio Xavier Salles-Cunha, ${ }^{2}$ \\ Filipe Amorim Braga, ${ }^{3}$ Rita de Cássia \\ dos Santos Moreira, ${ }^{4}$ \\ Joyce Annenberg Araújo dos Santos, ${ }^{4}$ \\ Thayná Lucilla Santos de Araújo, ${ }^{4}$ \\ Guilherme Benjamin Brandão Pitta ${ }^{5}$ \\ ${ }^{1}$ State University of Health Sciences of \\ Alagoas (UNCISAL); and Biotechnology \\ and Health, Northeast Network in \\ Biotechnology (RENORBIO), Maceió, \\ AL, Brazil; ${ }^{2}$ Visiting Professor, \\ Ultrasonographer, Maceió, AL, Brazil; \\ and Research Consultant, Itanhaém, SP, \\ Brazil and Jacksonville Beach, FL, \\ USA; ${ }^{3}$ Vascular Surgeon, \\ Ultrasonographer, Arapiraca, AL, \\ Brazil; ${ }^{4}$ Physiotherapy, University \\ Center Tiradentes, Maceió, AL, Brazil; \\ ${ }^{5}$ Northeast Network in Biotechnology \\ (RENORBIO); Federal University of \\ Rio Grande do Sul (UFRGS); and State \\ University of Health Sciences of Alagoas \\ (UNCISAL), Maceió, AL, Brazil
}

\footnotetext{
Abstract

Characterization of tissue by ultrasonography (CATUS) is a modern-day research endeavor intended to improve visual perception and image quantification. Visual perception increases with color Quantification focuses on pixel echo brightnesses. A previously presented case report demonstrated reappearance of lymphatic channels a few days after manual drainage.

Ultrasonographic images (US) of lymphatic leg and foot were quantitated and compared to a normal extremity based on proportions of pixels in specific brightness intervals. Anatomy evaluated included control-subcutaneous and lymphatic compartments. US with 256 brightness levels were obtained at the proximal, mid and distal leg and foot. Control and lymphatic Gray Scale Medians (GSM) and histograms were compared using t-test and Chi-square statistics.

Average GSM was $97 \pm 9$ (SD) (82-114, $\mathrm{n}=12$ images) for control, greater than $51 \pm 15(24-69, \mathrm{n}=12)$ for lymphedematous leg/foot $(\mathrm{P}<0.001)$. Control had $>99 \%$ of pixels with brightness in the muscle-fiber
}

range (41-196), in contrast to $62 \%$ for the lymphatic extremity $\quad(\mathrm{P}<0.001)$. Lymphedema averaged $7 \%, 3 \%, 15 \%$ and $14 \%$ of pixels in blood, blood/fat, fat and fat/muscle-like regions (0-4, 5-7, 8-26, 2740 brightness intervals). Such regions were visually interpreted as lymphatic channels or lakes.

Visual perception by colorization is subjective, but most people perceives details better, for example, during the day than at night. Furthermore, US images have 16 times more shades of gray, 256, than that perceived by the human visual system, 16 on average. Colorization improved perception of lymphatic channels and lakes by transforming blood echoes into red and lymphatic liquid with echoes similar to fat into yellow.

Pixel proportions in low brightness intervals were higher in the lymphatic than in the normal extremity. Lymphedema severity was quantified. The CATUS technique may be used to monitor treatment effects or disease evolution.

\section{Introduction}

The utility of ultrasonography (US) to describe lymphedema, in particular of the lower extremity, has been demonstrated in a variety of ways. ${ }^{1-8}$ We have shown the short duration of manual drainage by using a technique being known as characterization of tissue by ultrasonography (CATUS). ${ }^{9}$ CATUS is an expansion of Lal's pixel distribution analysis of the carotid plaque. ${ }^{10} \mathrm{~B}$ mode echogenicity intervals were defined for blood, fat, muscle, fiber and calcium, according to levels $0-4,8-26,41-76,112-$ 196 and 211-255 for an US image having 256 brightness amplitudes. The Gray Scale Median (GSM) is a single number used to represent an anatomic region. A multi-center study demonstrated, for example, that carotid plaques with GSM $<25$ have a high risk of stroke during stenting. ${ }^{11}$ CATUS has been applied to analyze: i) venous thrombi; ${ }^{12-15}$ ii) normal, abnormal and transplanted kidneys; ${ }^{16-18}$ iii) aneurysms; $;{ }^{19}$ iv) peripheral arterial disease ${ }^{20}$ and v) lymphedema, ${ }^{9}$ in addition to the carotid plaques. ${ }^{21,22}$ This manuscript is a fundamental description of the technique applied to a comparison between US images of: i) the leg and foot of a traditional lymphedematous lower extremity versus; ii) a control type, normal limb (Figure 1)
Correspondence: Vanessa Lôbo de Carvalho, State University of Health Sciences of Alagoas (UNCISAL); and Biotechnology and Health, Northeast Network in Biotechnology (RENORBIO), Rua Professor Manoel Coelho Neto 201, Jatiúca, Maceió, AL, CEP 57036710, Brazil.

E-mail: ftvanessa1981@gmail.com

Key words: Lymphedema; ultrasonography; brightness quantification.

Acknowledgments: we thank Arthur Ramos Hospital personnel, Maceio, AL, for allowing patient recruitment and ultrasound testing in hospital premises.

Contributions: VLC, design, patient recruitment, data collection, data analysis, manuscript writer-reviewer; SXSC, design, data collection, ultrasonographer, data analysis, manuscript writer; FAB, design, medical consultant, ultrasonographer, vascular laboratory director, manuscript reviewer; RCSM, JAAS, TLSA, patient recruitment, patient-care, ultrasound assistance, data collection, manuscript comments; GBBP, design, laboratory director, research director, manuscript reviewer

Conflict of interest: the authors declare no potential conflict of interest.

This work is licensed under a Creative Commons Attribution 4.0 License (by-nc 4.0).

C) Copyright V. Lôbo de Carvalho et al., 2018

Licensee PAGEPress, Italy

Veins and Lymphatics 2018; 7:7069

doi:10.4081/vl.2018.7069

\section{Materials and Methods}

US images were obtained at the medial aspect of the leg and dorsum of the foot. The proximal-upper, mid and distal-lower aspects of the leg were imaged. A Mindray 5 instrument and a 8-12 MHz linear transducer were employed. A peripheral vein set up used to study superficial venous reflux was employed for all images. The original leg venous set-up of the instrument was adapted by one of the authors. Usually, a instrumental venous set-up is designed to image femoropopliteal veins. The co-author re-selected items such as frequency range (8-12 MHz), shallow depth, gain according to his visual perception (G60 for his instrument), frame rate at 16 , and dynamic range at 70 to optimize his imaging of peripheral, superficial veins. Such peripheral veins included saphenous veins and related tributaries and perforating veins. Another coauthor selected this set-up for this investigation to image subcutaneous, superficial compartments in the leg. Practically, the 
set-up used was acceptable to two ultrasonographers among the authors. Depths were distinct 1 between control, $1.5 \mathrm{~cm}$, and lymphatic leg, $4.5 \mathrm{~cm}$, due to the larger volume of the lymphedematous tissue. Recalibration for uniformity was performed for each CATUS analysis using black as zero and similar fascial echoes or focus arrow as 200. The software program required redefinition of the 0 and 200 brightness levels. Lal's original version used blood and arterial adventitia for a 0190 scale. ${ }^{10}$ This application was not arterial and did not have standard arterial blood or adventitia as references. A distinct brightness had to be selected for the new 200 brighness. The author performing the CATUS analysis trusted the original images as representatives of the subjects' conditions and opted for references that did not alter significantly the original images.

CATUS was performed in anatomic compartments according to the analyst decision-making. Normal control images represented the subcutaneous tissue. The depth interval 0.1 to $0.6 \mathrm{~cm}$ encompassed all but one image analyzed. Patient's image represented regions with lymphatic channels and/or lakes. Average depth of a rectangular region analyzed was $0.5 \mathrm{~cm}$ to $2.2 \mathrm{~cm}$. The width encompassed most of the transducer imaging width available. Figure 2 demonstrates the versatility of a personalized program showing: i) Lal's criteria; ii) an equal interval-based echo subdivision; and iii) an expanded Lal-based tissue subdivision with 14 intervals: non-echogenic, hypoechogenic I, II, III and IV, echogenic I to IV, hyper-echogenic I to IV and saturated. The later was used for control-lymphedema comparison. Artificial colors were selected based on the analyst's perspective.

Percentages of pixels were calculated for each interval. Continuous brightness histograms, GSM, bar histograms and color imaging were part of the report. Data from 12 images were available for analysis both of the control subject (right and left) and the lymphedematous extremity. GSM were compared by Student's $t$-test and histogram pixel percentage data were compared using Chi-square statistics available with Excel.

\section{Results}

In general, average GSM was $97 \pm 9$ (SD-standard deviation) (minimum $=82$ maximum=114) for control, greater than $51 \pm 15$ (24-69) for the lymphedematous leg/foot $(\mathrm{P}<0.001)$. Control had $>99 \%$ of pixels with brightness in the muscle-fiber range (41-196), in contrast to $62 \%$ for the lymphatic extremity $\quad(\mathrm{P}<0.001)$. Lymphedema averaged $7 \%, 3 \%, 15 \%$ and $14 \%$ of the pixels in blood, blood/fat, fat and fat/muscle-like regions (0-4, 5-7, 8-26 and 27-40 brightness intervals). The lowest GSM values were obtained in the foot of either subject.

As a technical note, the new brightness 0 , based on a black region of the image, was the same for all 24 images. The new 200 brightness averaged $4 \%$ higher for the control images, 203, versus 194 for the lymphedematous extremity.

\section{Discussion}

This report described how the CATUS technique can be useful to distinguish echogenic differences between a lymphedematous extremity and a control limb. This initial analysis suggested that additional research could be performed to quantitate lymphedema and to follow lymphedema treatment or progression of disease. It also opened the opportunity to study other types of edemas in the leg or even in the upper extremity.

In particular, differences were demonstrated based on the presence or normal absence of lymphatic channels or lakes as

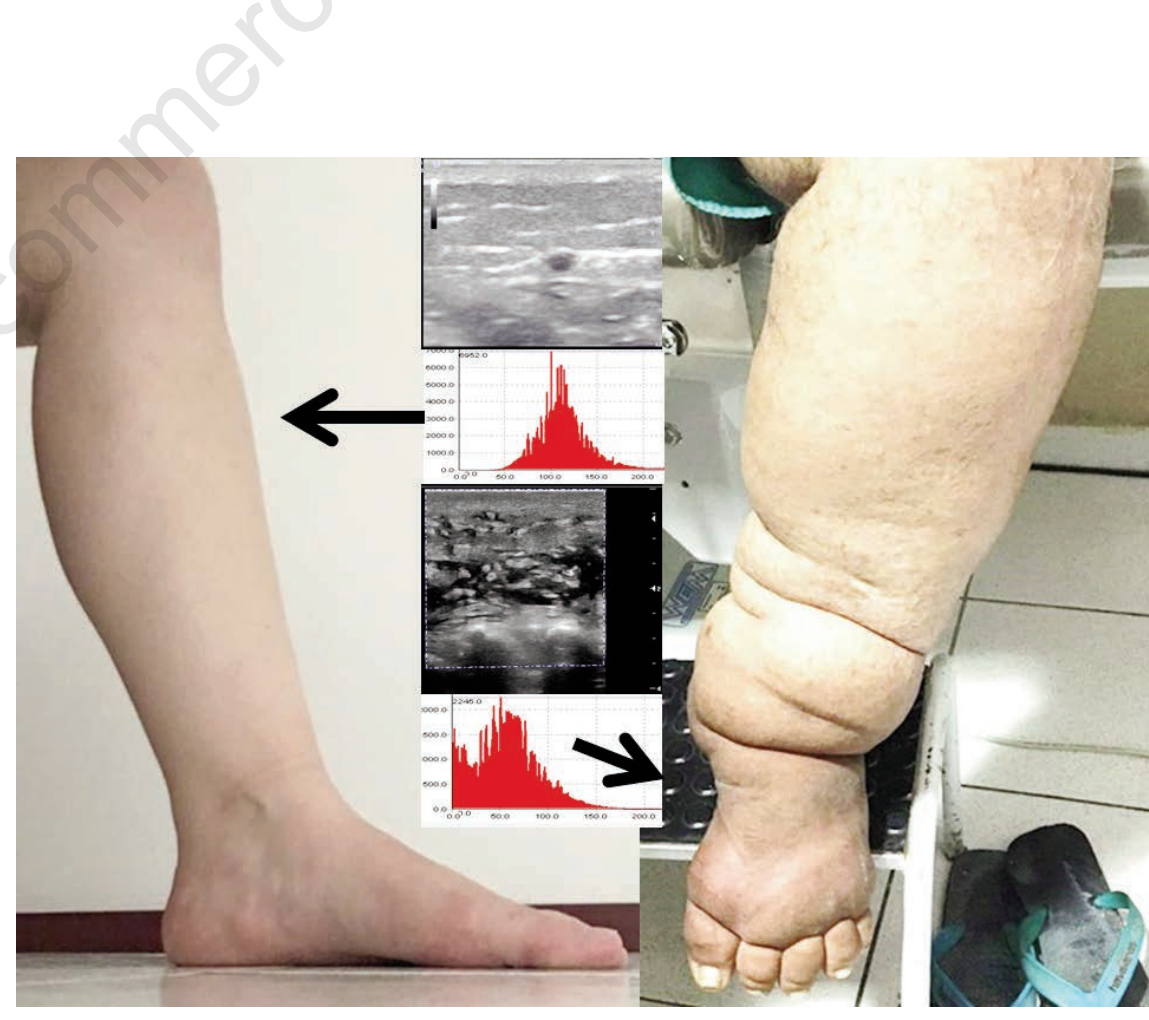

Figure 1. Photographies of control and lymphedema extremities and corresponding ultrasound images. The continuous histograms show differences in echogenicity among two large anatomic regions. Actual comparative analysis was restricted to subcutaneous control compartment and lymphatic compartment with channels and lakes. shown in Figure 3. Our poster suggested that manual drainage sequence could be reviewer, however, also commented that fibrosis and hyper-echogenicity should be better to quantitate lymphedema worsening. Indeed, Figure 4 probably indicates that the upper leg of this patient is in worse condition than the lower leg or foot. Our yet to be reported experience has raised some hypotheses that deserve CATUS investigation such as: i) channels and lakes are more common in the foot than in the leg; ii) lymphedematous legs also have hyperechogenic regions; and iii) presence versus absence of channels may determine better or worse response to treatment. Fibrosis in cutaneous, subcutaneous and superficial or deep compartments without regional lymphatic channels should represent worst-case condition.

Volumetric changes of the subcutaneous and subfacial, muscular compartments have been demonstrated long time ago. ${ }^{1}$ US images of dilated lymphatic channels have been published for conditions such as lymphatic flow obstruction. ${ }^{2}$ Worms moving in US images of the lymphatic tract, the filaria dance sign, has been an impressive finding. ${ }^{3}$ Visual impressions by experts allowed semi-quantitative analysis of skin and superficial compartments. ${ }^{4-6}$ Elastography optimized by ultrasound observations. ${ }^{9}$ A 
has been applied to lymphedema. ${ }^{7-8}$ CATUS performed under compression conditions could provide data comparable to elastographic information.

Echogenicity and artificial colorization of edematous conditions may be a tissue research trend in the following decade. ${ }^{23}$ Gray scale analysis, in general, is a growing field, particularly in research. ${ }^{24}$ As an example, a peripheral venous thrombus with a hyperechogenic rock at the tip may be a more dangerous embolus than a hypoe- chogenic thrombus. ${ }^{12}$ Also, hyperechogenic chronic venous obstruction may be permeated with trapped blood or hypoechogenic new thrombi causing localized symptoms for years. These opinions corroborate investigations that recommend ultrasound as an
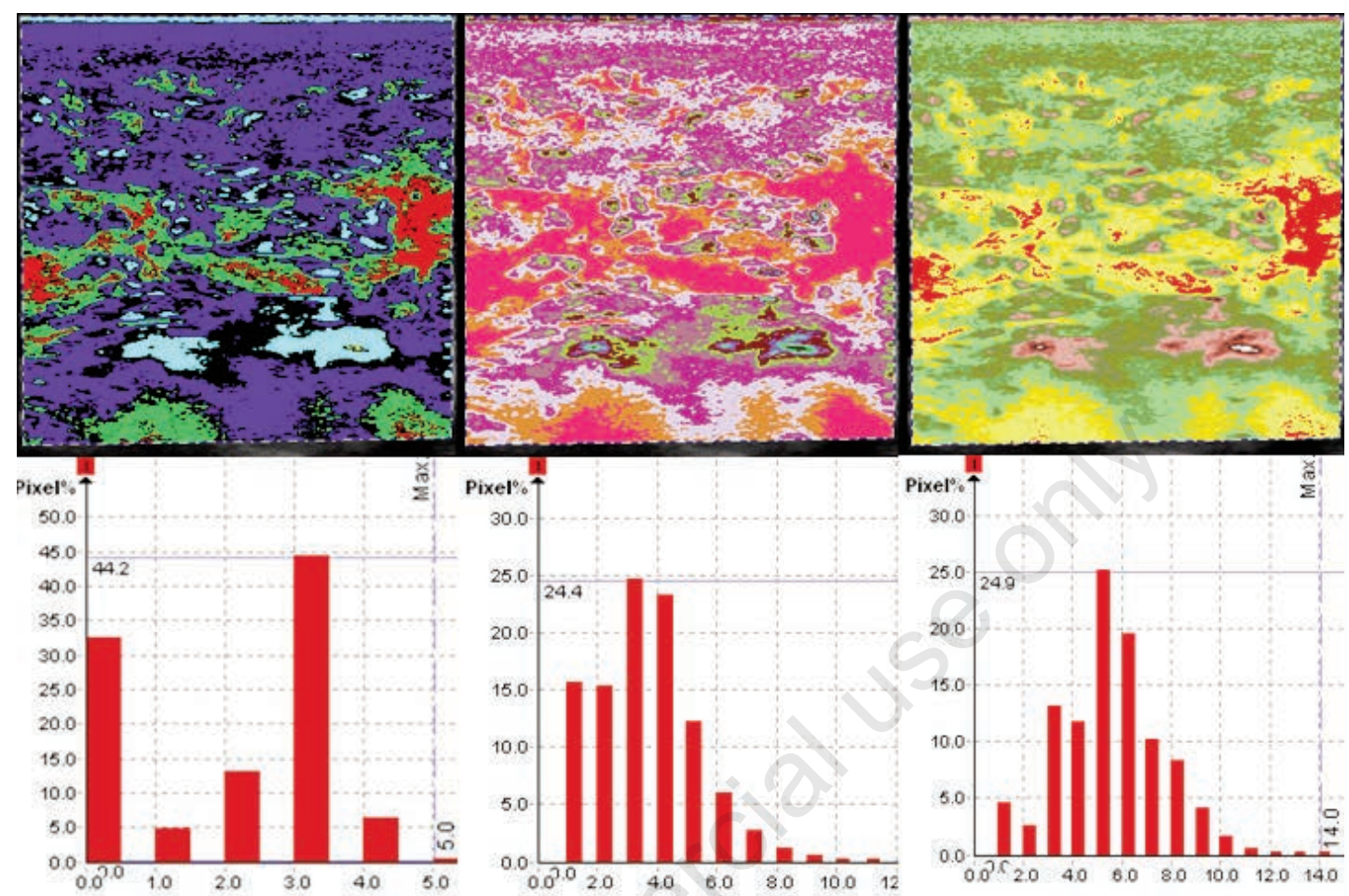

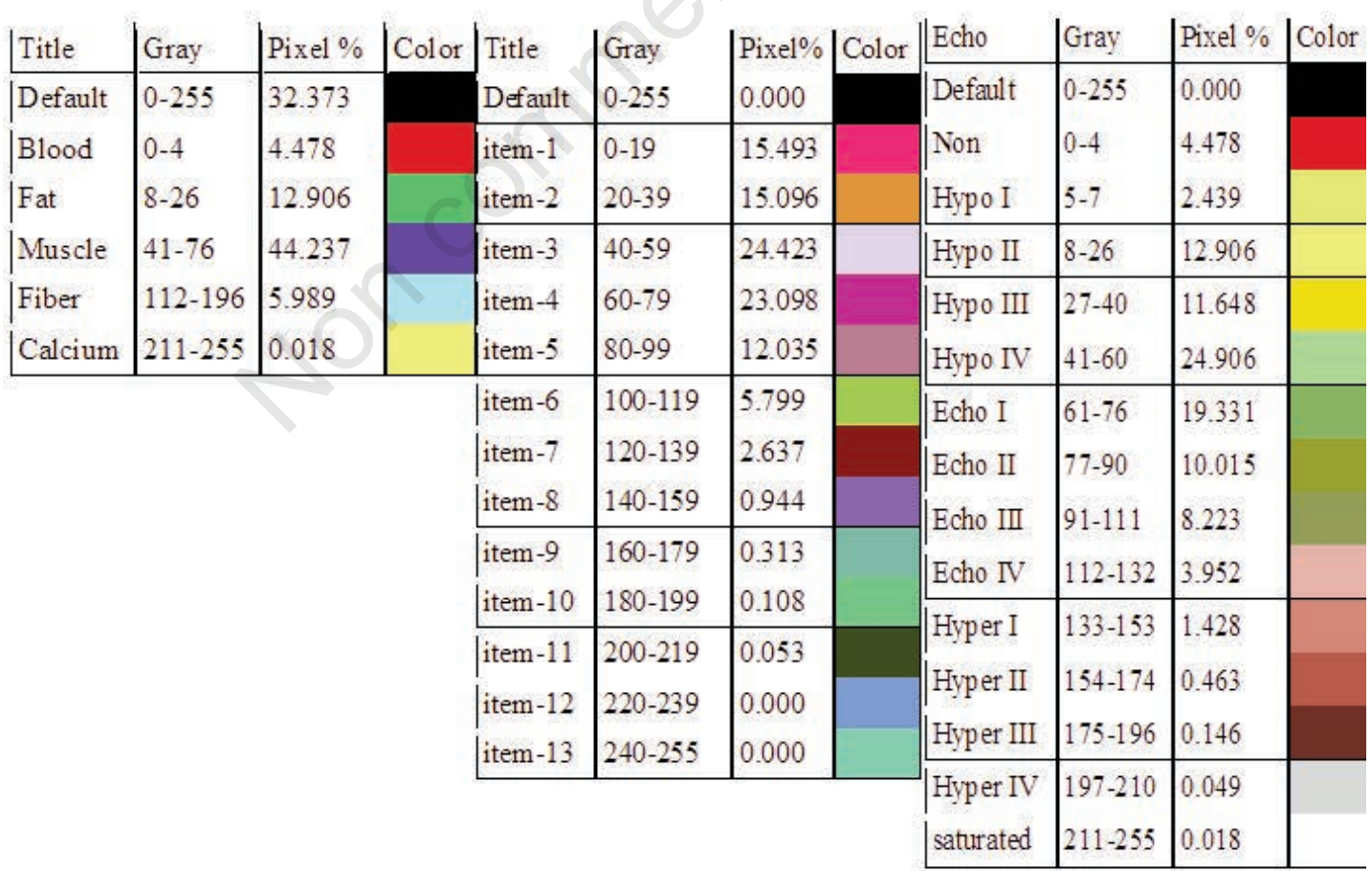

Figure 2. Examples of characterization of tissue based on ultrasound (CATUS). From reader's left to right: i) Lal's pixel distribution based on blood, fat, muscle, fiber and calcium; classification default occurred in $32 \%$ of pixels with brightness in between such intervals; ii) pixel distribution in intervals with 20 brightness values; and iii) expanded Lal's classification showing default intervals and subdivision of muscle and fiber intervals. Artificial colorization was arbitrary and may vary according to the observer's visual preferences. Brightness intervals may be defined for each individual application. 


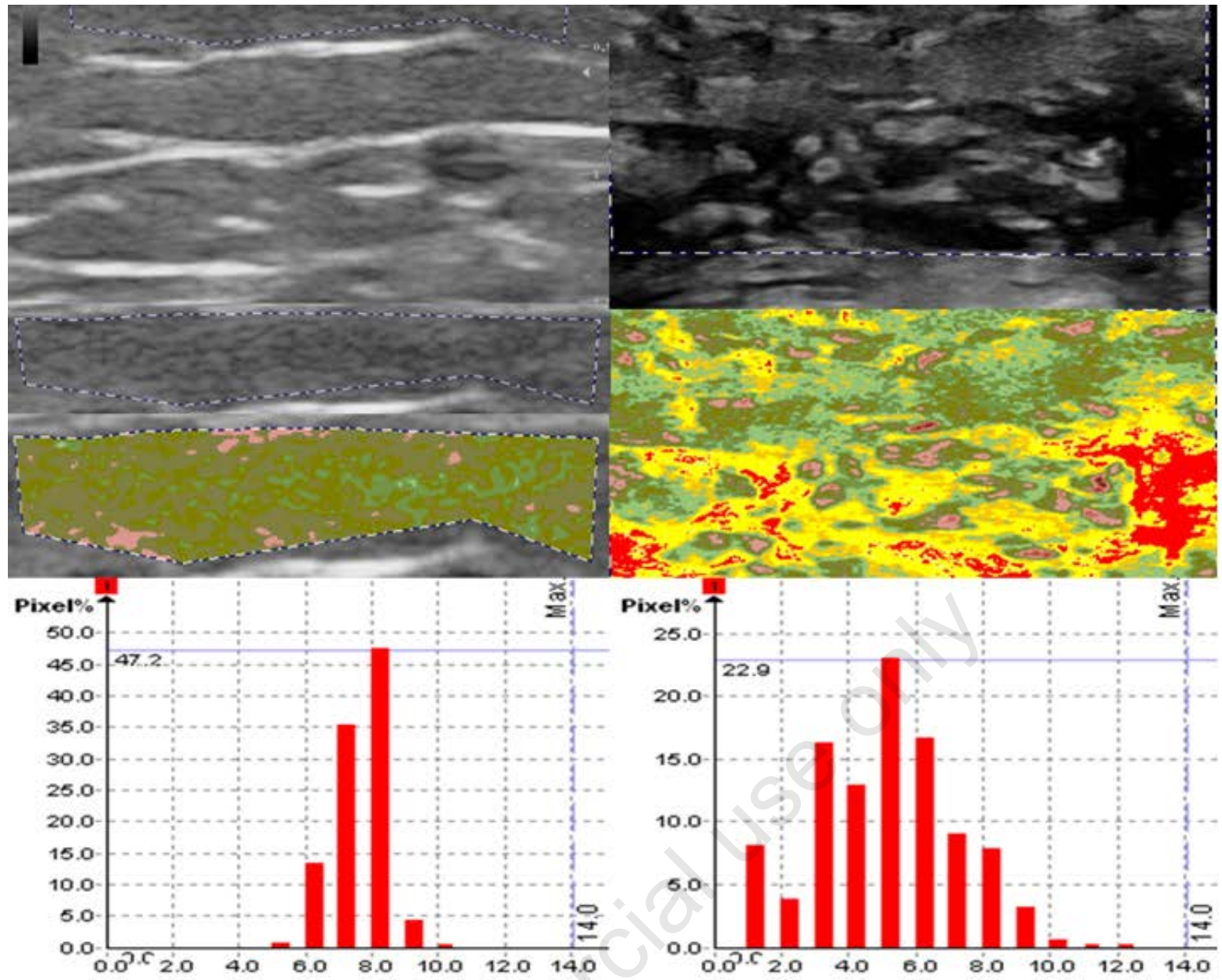

\section{Proportions of pixels per brightness intervals}

\section{1 blood like}

\section{2 bloodfat}

\section{3 fat like}

4 fat muscle

5 muscle like

6 muscle like

$13 \%$

7 muscle fiber

$35 \%$

8 muscle fiber

9 fiber like

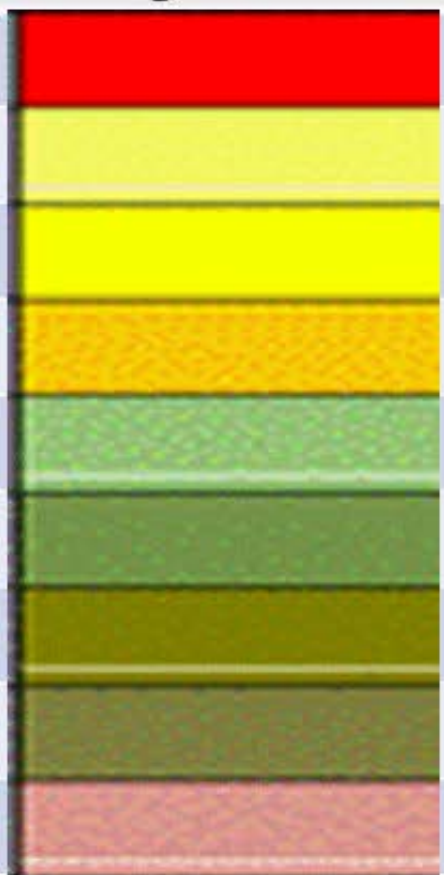

$8 \%$

$3 \%$

$16 \%$

$13 \%$

$23 \%$

$16 \%$

$9 \%$

$8 \%$

$3 \%$

Figure 3. Normal control (reader's left) and lymphedematous leg comparison. From top to bottom: i) original ultrasound image; ii) artificial colorization; iii) bar graph histogram representing proportions of pixels according to brightness intervals; iv) table with percentages of pixels according to color intervals. Brightness associations: red-blood, yellow-fat, green-muscle, brown-muscle/fiber, light purple-fiber. Lymphedema presented enlarged lymph channels supposedly filled with blood plasma and/or fatty liquids. 

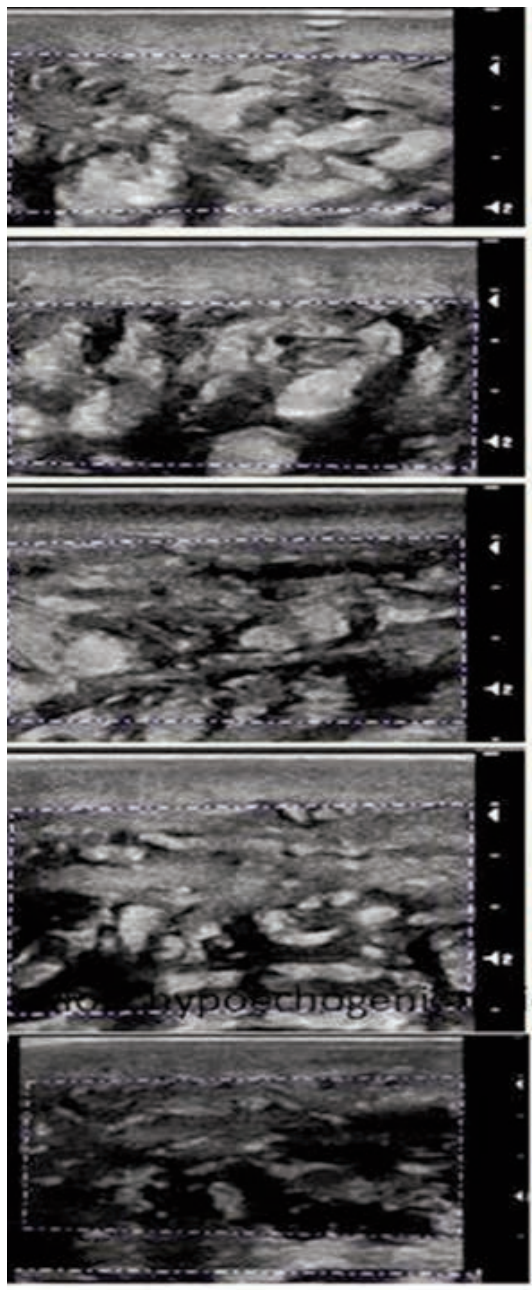

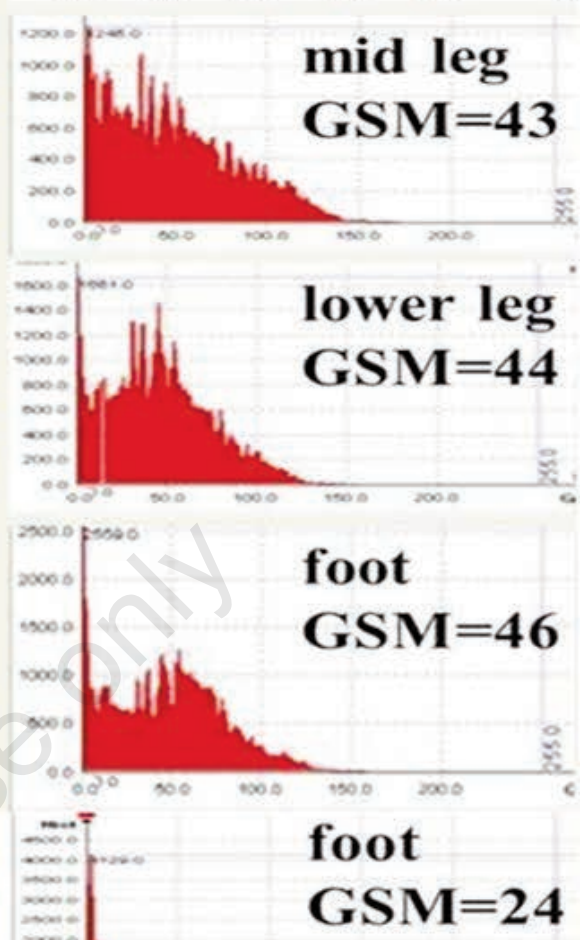

Figure 4. Lymphedematous leg. From reader's left to right: original ultrasound image, artificial colorization and continuous histogram based on pixel brightness. Brightness associations: red-blood, yellow-fat, green-muscle, brown-muscle/fiber, light purple-fiber. Upper leg image had a higher gray scale image (GSM) value. Image at the bottom demonstrates worst case condition, or most hypo-echogenic region, observed in the foot.

indicator of treatment postures..$^{25}$

CATUS was programmed to provide the user with alternatives and knowledge on how the analytical process works. It permits specific analysis of a measurement in question. Data collection, however, must avoid variability. Similar set up and similar US knobs must be uniform for comparisons. Re-scaling does not compensate for all variability issues. A simple application would be to follow the same patient with the same technique.

CATUS is a subset of CATIM, characterization of tissue by imaging. Photographic CATIM of diabetic and venous ulcers have been published. ${ }^{26,27}$ CATUS improves perception by artificial colorization and permits quantitative analysis based on percentages of pixels in specific brightness intervals. The physiological logic behind CATUS-CATIM is that the human brain perceives color better than gray, like the expression night and day. Furthermore, the human eye only distinguishes, on average, 16 gray levels while an ultrasound image usually have 16 times more tons of gray, $256 .{ }^{28}$

\section{Conclusions}

The CATUS technique allowed quantitative comparison showing lower echogenicity in the lymphatic extremity as compared to control. Lower echogenic regions were perceived as channels and/or lakes. Research is still evolving in several areas including edema. Artificial colorization may improve perception pending individual tendencies. Pixel distribution percentages upgrade imaging analysis by quantification. Consistent US knobology and patient follow-up under similar conditions are recommended.

\section{References}

1. Doldi SB, Lattuada E, Zappa MA, et al. Ultrasonography of extremity lymphedema. Lymphology 1992;25:12933.

2. Drinan KJ, Wolfson PM, Steinitz D, et al. Duplex imaging in lymphedema. J Vasc Technol 1993;17:23-6.

3. Amaral F, Dreyer G, Figueredo JS, et al. Adult worms detected by ultrasonography in human bancroftian filariasis. Am J Trop Med Hyg 1994;50:753-7.

4. Suehiro K, Morikage N, Murakami M, et al. Significance of ultrasound examination of skin and subcutaneous tissue in secondary lower extremity lym- 
phedema. Ann Vasc Dis 2013;6:180-8.

5. Suehiro K, Morikage N, Murakami M, et al. Subcutaneous tissue ultrasonography in legs with dependent edema and secondary lymphedema. Ann Vasc Dis 2014;7:21-7.

6. Suehiro K, Morikage N, Murakami M, et al. A study of increase in leg volume during complex physical therapy for leg lymphedema using subcutaneous tissue ultrasonography. J Vasc Surg Venous Lymphat Disord 2015;3:295-302.

7. Suehiro K, Morikage N, Murakami M, et al. Skin and subcutaneous tissue strain in legs with lymphedema and lipodermatosclerosis. Ultrasound Med Biol 2015;41:1577-83.

8. Suehiro K, Kakutani H, Nakamura K, et al. Immediate changes to skin and subcutaneous tissue strains following manual lymph drainage in legs with lymphedema. Ann Vasc Dis 2016;9:30-4.

9. Salles-Cunha SX, Silveira SAF, Menezes FH. Case report: ultrasound virtual histology to grade treatment of lower extremity lymphedema. Poster presented at the 36th Society for Vascular Ultrasound Annual Meeting, Washington, DC, June 7-9, 2012.

10. Lal BK, Hobson RW II, Pappas PJ, et al. Pixel distribution analysis of Bmode ultrasound scan images predicts histologic features of atherosclerotic carotid plaques. J Vasc Surg 2002;35:1210-17.

11. Biasi GM, Froio A, Diethrich EB, et al. Carotid plaque echolucency increases the risk of stroke in carotid stenting: the Imaging in Carotid Angioplasty and Risk Of Stroke (ICAROS) study. Circulation 2004;110:756-62.

12. Salles-Cunha SX. Duplex scanning for acute venous thrombosis. In: Peter Gloviczki, ed. Handbook of venous disorders, Guidelines of the American Venous Forum, 3rd ed. London: Edward Arnold, Publisher; 2009. pp 129-41.
13. Cassou-Birckholz MF, Engelhorn CA, Salles-Cunha SX, et al. Assessment of deep venous thrombosis by grayscale median analysis of ultrasound images. Ultrasound Q 2011;27:55-61.

14. Barros FS, Sandri JL, Prezotti BB, et al. Pulmonary embolism in a rare association to a floating thrombus detected by ultrasound in the basilic vein at the distal arm. Rev Bras Ecocardiogr Imagem Cardiovasc 2011;24:89-92.

15. Salles Cunha SX, Varjão de Oliveira Guimaraes AF. Complementary role of thermography in the diagnosis of subclavian vein thrombosis: case report. Poster presented at 40th Congress of the Brazilian Society of Angiology and Vascular Surgery, Florianópolis, SC, September 30 to October 5, 2013.

16. Valiente Engelhorn AL, Engelhorn CA, Salles-Cunha SX. Initial evaluation of virtual histology ultrasonographic techniques applied to a case of renal transplant. J Vasc Ultrasound 2015;39:142-4.

17. Valiente Engelhorn AL, Engelhorn CA, Salles-Cunha SX, et al. Ultrasound tissue characterization of the normal kidney. Ultrasound Q 2012;28:275-80.

18. Valiente Engelhorn AL, Engelhorn CA, Salles-Cunha SX. Ultrasonographic tissue characterization of kidneys in patients with unilateral renal artery stenosis. J Vasc Ultrasound 2016;40:705.

19. Salles-Cunha SX. Technical note: Ultrasonographic evaluation of aortic aneurysms treated with endoprosthesis. J Vasc Bras 2012;11:150-3.

20. Marks NA, Ascher E, Hingorani AP, et al. Gray-scale median of the atherosclerotic plaque can predict success of lumen re-entry during subintimal femoral-popliteal angioplasty. J Vasc Surg 2008;47:109-16.

21. Menezes FH, Silveira TC, Silveira SAF, et al. Preliminary comparisons between in vivo ultrasonographic virtual histol- ogy and histopathological findings of endarterectomized carotid plaque. J Vasc Bras 2013;12:193-201.

22. Barros FS, Pontes SM, Prezotti BB, et al. Floating thrombus in the internal carotid artery: Surgical planning defined by vascular ultrasound. Arq Bras Cardiol: Imagem Cardiovasc 2013;26:335-40.

23. Ueda-luchi T, Ohno N, Miyati T, et al. Assessment of the interstitial fluid in the subcutaneous tissue of healthy adults using ultrasonography. Sage Open Medicine 2015;3:2050312115613351.

24. Harris-Love MO, Seamon BA, Teixeira C, Ismail C. Ultrasound estimates of muscle quality in older adults: reliability and comparison of Photoshop and ImageJ for the grayscale analysis of muscle echogenicity. Peer J 2016;4:e1721.

25. Prandoni P, Prins MH, Lensing AW, et al. AESOPUS Investigators. Residual thrombosis on ultrasonography to guide the duration of anticoagulation in patients with deep venous thrombosis: a randomized trial. Ann Intern Med 2009; 150:577-85.

26. Pereira VHH, Costa Filho EM, Santos FTA, et al. Photographic image tissue characterization of the ulcerated diabetic foot during treatment: technical note. J Vasc Bras 2013;12:303-7.

27. Santos FTA, Rocha CA, Salles-Cunha $\mathrm{SX}$, et al. Tissue characterization by photographic imaging during treatment of chronic venous ulcer: technical note. J Vasc Bras 2015;14:177-81.

28. Beach KW, Paun M, Primozich JF. Principles and instruments of diagnostic ultrasound and Doppler ultrasound. In: Aburahma AF, Bergan JJ, eds. Noninvasive vascular diagnosis: a practical guide to therapy, 2nd ed. London: Springer-Verlag; 2007. pp 27. 